\title{
A Study on the Factors Affecting the Efficiency of Regional Trade Circulation in China
}

\section{Chu Denghong, Li Na}

School of Economics, Shanghai University, Shanghai, China

\section{Email address:}

chudenghong@163.com (Chu Denghong),nali1535@163.com(Li Na)

\section{To cite this article:}

Chu Deng Hong, Li Na. A Study on the Factors Affecting the Efficiency of Regional Trade Circulation in China. Science Innovation. Vol. 5, No. 3, 2017, pp. 151-155. doi: 10.11648/j.si.20170503.15

Received: March 27, 2017; Accepted: April 18, 2017; Published: April 20, 2017

\begin{abstract}
The scale of China's circulation industry is expanding, and the efficiency of commodity circulation has become the most important factor in the development of national competitiveness. While the development efficiency of the circulation industry in different regions is quite different. Factors affecting the efficiency of circulation in different regions of the degree of action is different. This paper summarizes the nine factors that affect the efficiency of circulation. On the basis of this, the paper establishes a multiple regression model to analyze the effect of factors on the efficiency of circulation in eastern, central and western regions. And further put forward the proposal to improve the efficiency of China's commodity circulation.
\end{abstract}

Keywords: Circulation Efficiency, Influencing Factors, Linear Regression, Empirical Research

\section{中国区域商贸流通效率的影响因素研究}

储灯红, 李娜

经济学院, 上海大学, 上海, 中国

邮箱

chudenghong@163.com（储灯红）, nali1535@163.com（李娜）

摘要: 中国流通产业的规模扩大, 商品流通效率的成为国家竞争力发展的重中之重。而不同地区存在流通业发展存在 较大差异。影响流通效率的因素在不同地区作用程度不同。本文分析总结出影响流通效率的三个层面九个要素, 并在 此基础上建立多元回归模型分析了东部、中部、西部三大区域影响流通效率的作用效果。进一步提出了提高我国区域 商品流通效率的建议。

关键词: 流通效率, 影响因素, 线性回归, 实证研究

\section{1. 引言}

随着我国经济进入新常态, 依赖制造业发展带来的国 家竞争力优势不断弱化。在此背景下, 我国商贸流通业逐 渐成为经济发展的中心环节, 是国民经济发展的重要产业。 国务院《关于推进国内贸易流通现代化建设法制化营商环 境》提出 “提高流通效率, 降低流通成本”, 说明流通效
率的提高将成为流通产业进一步发展的主题。但是, 研究 表明, 我国不同地区的流通业发展存在明显差异, 而且流 通业整体发展水平滞后于经济发展总水平 [1]。主要原因 在于流通的质量和水平未与流通规模的增长实现同步。同 时国家协调各个地区的发展存在一定的难度。

影响流通效率的要素成为达成提高流通效率目标重 要的突破口。由于中国各个地区在地理、文化等方面的差 
异较大, 不同地区影响流通产业效率的因素影响程度也不 尽相同。根据不同地区特征，对商贸流通效率采取不同的 改进措施促进流通业质的发展是国家和企业发展流通业 的一个重要方向。

传统流通理论在研究我国商贸流通效率较少从地区 差异的角度进行研究。而在地区差异的研究中, 学者在进 行流通效率分析时, 着重关注单一影响指标的影响, 未涉 及普遍的要素分析。另外, 部分学者从产业的角度, 根据 各省数据研究出流通行业中各个影响要素的作用方向和 作用程度, 为流通效率的提高提出了普遍适用的建议。本 文在前人研究的基础上, 着重分析不同地区各个影响因素 的影响程度, 以期找到各个地区流通效率发展的 “特定” 路径。

\section{2. 文献综述}

由于影响流通效率的因素很多, 学者在对影响因素进 行研究时, 从不同的角度提出了不同的意见。根据分析商 品流通的层面不同, 可以把影响流通要素的因素分为以下 三个层面。

\section{1. 宏观层面影响流通效率的因素研究}

从宏观层面分析, 对流通效率有影响的要素主要是流 通产业所在的经济环境, 经济环境对流通效率提高上发挥 了基础性的作用。我国工业化和城镇化的进程推动着各行 各业的发展, 流通产业也不例外。随着城镇化的加快, 居 民对流通的需求也进一步扩大, 促使流通产业升级发展。 城镇化率是普遍考虑的宏观层面的影响因素 [2]。市场化 水平作为衡量中国市场经济发展的程度, 市场体系的完善 也是流通产业发展的重要前提 [3]。市场化水平从需求的 方面对商贸流通效率产生正向的影响。同时, 由于流通产 业的发展特性, 特别是互联网和电子商务的发展, 其市场 需求趋于国际化, 对流通产业信息技术的要求趋于多元化, 地区开放化程度也会影响流通效率。

\section{2. 行业层面影响流通效率的因素研究}

从行业层面分析, 对流通行业整体效率影响的主要因 素有政府参与程度、物流发展水平和行业市场结构。政府 参与主要起到对流通行业发展的促进作用, 通过制度作用 于其发展。学者依绍华 (2014) [4]认为我国的流通产业 公共支撑体系缺乏国家层面的统一发展规划, 政府参与提 高流通领域信息传递和处理的效率。流通业发展从实体商 品流通的角度来看, 其效率往往取决于物流业的发展水平。 姜曾伟（2008）[5]提出物流是衡量一个国家和地区流通 现代化程度的重要标志。学者王之泰 (2013) [6] 论述了 物流成本是流通成本最重要的组成部分。而在流通产业中 物流的衡量主要在于其交通运输基础设施的建设, “最后 一公里” 的配送便是其发展的重要里程。从市场结构的角 度出发, 流通效率主要依赖于市场的规模化和集中化。连 锁化经营的发展意味着行业组织结构的优化, 从而实现规
模效应, 改善原来散乱的市场结构。章迪平等 (2009) [7] 认为扩大企业规模、提高产业集中度能够提高流通绩效。

\section{3. 企业层面影响流通效率的因素研究}

从企业层面分析, 各地区本身流通企业的数量及其从 业人数是地区流通效率提高的基础。同时，流通各节点企 业之间的关系也是影响流通的一个重要因素, 现有研究集 中讨论了流通渠道长度对流通效率的影响。谢莉娟 (2013) [8]提出流通商借助渠道优势整合供应链趋势日益强化并 分析除基于分销管理的渠道关系能够在拓展至段落供应 链的整合关系中获得效率增进。而在企业内部经营整合的 过程中, 随着流通企业的商业模式和经营方式愈发成熟, 影响商品在企业内滞留时间的主要是信息化因素, 信息化 水平能带来企业流程的优化升级 [9]。

现有的研究在考虑商贸流通效率的因素时, 考虑的范 围很广泛，涉及的层面也不同。主要从整体的流通效率进 行了综合考虑, 对于不同地区的差异性并没有多做阐述。 而考虑了地区差异的研究中, 涉及的因素选择也各有侧重, 没有综合考虑各个层面的因素在不同地区的特征性。本文 在现有研究的基础上, 通过以上对流通效率不同层面影响 因素的分析和总结, 采用回归模型进行数据分析, 进一步 对不同地区的主要影响因素进行研究。

\section{3. 模型设定与变量设置}

\section{1. 变量设置}

为构建分析流通效率影响因素的多元回归分析模型, 本文选取批发和零售业增加值作为衡量流通效率的产出 指标 [10]。解释变量包括三个层面共九个影响因素。

基于数据可获得性以及保证分析结果的准确性, 各解 释变量的衡量如下表（表1）。（1）城镇化率（URBAN） 用城镇人口比来进行衡量。（2）市场化水平 (MARKFG) 根据㚞纲的市场化指数进行测度, 其中 2010-2014年的数 据根据计算得到。（3）对外开放程度 (OPEN) 以进出口 贸易的金额与各省GDP的比值来计算。（4）政府参与程度 （GOV）用地方财政支出与GDP的比值来衡量。（5）物流 发展水平主要在于其物流基础设施的建设, 用INFRA表示, 根据学者达成的一般计算方法来进行测量, 用各地区的公 路、铁路和水路里程之和与各地区面积的比值来计算。(6) 连锁化水平 (CHAIN) 反映零售企业连锁经营的程度, 用 地区连锁企业从业人数与零售企业从业人数之比来表示。 （7）流通企业从业状况主要从劳动力从业情况来进行说 明, 用LABOR表示, 采取零售企业从业人数占全地区总人 数的比值进行描述。（8）流通渠道长度 (LENGTH) 根据 之前多数研究学者使用的一般方法进行衡量, 即选用以限 额以上批发企业的销售额与零售企业销售总额之间的比 例。（9）信息化程度（INTER）主要反映流通企业内部流 通的效率，但是由于各企业采用信息系统的程度不一, 衡 量有很大的困难。借鉴王晓东等 [11]的方法, 采用各省人 均互联网接入端口数作为变量设置。 
表1 流通效率影响因素变量设置。

\begin{tabular}{llll}
\hline 一级变量 & 二级变量 & 变量表达 & 变量编码 \\
\hline \multirow{3}{*}{ 宏观因素 } & 城镇化率 & 城镇人口比 & URBAN \\
& 市场化水平 & 市场化指数 & MARKFG \\
& 对外开放程度 & 进出口与各省GDP的比 & OPEN \\
& 政府参与程度 & 各区财政支出占该地区的国内生产总值的比重 & GOV \\
行业因素 & 物流发展水平 & 各省的公路里程、水路里程与铁路里程之和与省区面积的比 & INFRA \\
& 连锁化水平 & 地区连锁企业从业人数与零售企业从业人数之比 & CHAIN \\
& 流通企业从业状况 & 零售企业从业人数占全地区总人数的比 & LABOR \\
企业因素 & 流通渠道长度 & 以限额以上批发企业销售总额与零售企业总销售额之比 & LENGTH \\
& 信息化程度 & 各区人均互联网宽带接入端口数 & INT \\
\hline
\end{tabular}

\section{2. 模型建立}

为了研究在不同地区商贸流通效率与各影响因素之 间的关系, 本文采取一个以下的多元回归模型进行计量分 析:

effect $_{i}=\beta_{0}+\beta_{1}$ urban $_{i}+\beta_{2}$ markf $_{i}+\beta_{3}$ open $_{i}+\beta_{4}$ gov $_{i}+$ $\beta_{5}$ infra $_{i}+\beta_{6}$ chain $_{i}+\beta_{7}$ labor $_{i}+\beta_{8}$ length $_{i}+\beta_{9}$ int $_{i}$

其中, $i=1,2,3$,分别代表东部、中部、西部。 $u_{r b a n}$ 代 表区域 $i$ 的城镇化率; $\operatorname{markf} g_{i}$ 代表区域 $i$ 的市场化水平; $g o v_{i}$ 代表区域 $i$ 的政府参与程度; infra $a_{i}$ 代表区域 $i$ 的物流 发展水平; chain $_{i}$ 代表区域 $i$ 的连锁化水平; labor ${ }_{i}$ 代表区 域 $i$ 的零售企业从业状况; lengt $h_{i}$ 代表区域 $i$ 的流通渠道程 度; int $_{i}$ 代表区域 $i$ 的信息化程度。

\section{3. 数据来源}

本文数据来自国家统计局《中国统计年鉴》和万德统 计数据库。选取了各省2001-2014年共14年的数据进行分 析。为方便得到东部、中部、西部的区域数据, 本文选取 各区域所包含省区的变量数据的加权平均作为最终结果。 并将数据统一口径, 进行了归一化处理。经过处理后的数 据主要描述见表2（西部）。

表2 西部归一化处理后数据描述分析。

\begin{tabular}{llllll}
\hline & CHAIN & EFFECT & GOV & INFRA & LABOR \\
\hline Mean & 0.31 & 0.39 & 0.47 & 0.52 & 0.25 \\
Median & 0.20 & 0.28 & 0.33 & 0.65 & 0.06 \\
Maximum & 1.00 & 1.00 & 1.00 & 1.00 & 1.00 \\
Minimum & 0.00 & 0.00 & 0.00 & 0.00 & 0.00 \\
Std. Dev. & 0.26 & 0.34 & 0.38 & 0.39 & 0.35 \\
Skewness & 1.45 & 0.60 & 0.25 & -0.33 & 1.42 \\
Kurtosis & 4.69 & 1.98 & 1.38 & 1.42 & 3.46 \\
& INT & LENGTH & MARKFG & 0 PEN & URBAN \\
Mean & 0.31 & 0.41 & 0.49 & 0.47 & 0.45 \\
Median & 0.19 & 0.39 & 0.46 & 0.43 & 0.40 \\
Maximum & 1.00 & 1.00 & 1.00 & 1.00 & 1.00 \\
Minimum & 0.00 & 0.00 & 0.00 & 0.00 & 0.00 \\
Std. Dev. & 0.34 & 0.35 & 0.30 & 0.33 & 0.32 \\
Skewness & 0.91 & 0.24 & 0.09 & 0.31 & 0.30 \\
Kurtosis & 2.45 & 1.62 & 1.86 & 1.97 & 1.89 \\
\hline
\end{tabular}

\section{4. 实证结果与分析}

本文使用软件工具EVIEWS 8对东部、中部、西部的数 据进行了多元线性回归分析, 回归结果如下:

表3 多元线性回归结果。

\begin{tabular}{llll}
\hline & 东部 & 中部 & 西部 \\
\hline C & 0.130129 & 0.060947 & 0.047975 \\
& $(-0.479233)$ & $(1.156674)$ & $(1.827485)$ \\
URBAN & 0.082074 & 0.423756 & 0.399003 \\
& $(2.720446) * *$ & $(0.715591)$ & $(4.060668) * *$ \\
MARKFG & -0.075953 & -0.102373 & -0.014664 \\
& $(-0.42343)$ & $(-2.00111)$ & $(-5.168189) * * *$ \\
OPEN & 0.126371 & 0.069012 & 0.076114 \\
& $(-0.999585)$ & $(2.22218) *$ & $(2.993295) * *$ \\
GOV & 0.451908 & 0.136748 & 0.164846 \\
& $(2.713439) * *$ & $(3.074018) * *$ & $(4.031194) * *$ \\
INFRA & -0.011076 & -0.060004 & -0.032217 \\
& $(-0.554469)$ & $(-0.167662)$ & $(-3.822819) * *$ \\
CHAIN & -0.129952 & -0.036837 & -0.062255 \\
& $(-1.215834)$ & $(-1.020992)$ & $(-2.532455) *$ \\
LABOR & 0.010971 & 0.067143 & 0.108105 \\
& $(1.286574)$ & $(0.080894)$ & $(1.658364)$ \\
LENGTH & -0.04424 & -0.050626 & -0.069499 \\
& $(-0.741371)$ & $(-1.129888)$ & $(-1.524542)$ \\
INT & 0.301428 & 0.41627 & 0.288767 \\
& $(1.576674)$ & $(1.655995)$ & $(4.560286) * *$ \\
\hline
\end{tabular}

注： $*$ 表示在 $10 \%$ 水平上显著, $* *$ 表示估计系数在 $5 \%$ 水平上显著, $* * *$ 表 示估计系数在 $1 \%$ 水平上显著。小括号内为基于标准差计算得到的 $\mathrm{t}$ 统计 量。

东部、中部、西部三个回归方程的拟合优度均在 0.99 以上，说明回归方程整体上是显著的。对于东部而言，比 较显著的影响因素是城镇化率和政府参与程度, 其他一些 要素在整体考虑的情形下并不明显与流通产业绩效相关, 主要原因在于东部地区的对外开放程度、流通业的从业状 况等方面相对于中部和西部而言都发展到比较成熟的阶 段了, 其对流通产业的影响没有那么明显。而城镇化率和 政府参与程度在流通发展中起着比较重要的作用, 同时这 两个因素与其他因素的相关性比较强, 其他因素的不明显 也是受到了多重共线性的影响。

中部地区跟东部地区类似, 在六个影响因素中有着显 著影响的因素也只有两个, 但是这两个因素并不相同, 分 别是对外开放程度和政府参与程度。中部地区相对于东部 而言, 由于地理位置的因素, 对外开发程度明显低于东部 水平, 在这样的前提下, 流通业的发展与对外开放程度之 
间的关系就显得比较明朗。与东部和中部不同的是, 对西 部地区流通效率影响明显的因素有六个之多, 主要原因是 西部地区流通业发展缓慢, 各方协调才能促进整个流通行 业的发展, 而且由于特殊的地理因素, 流通业的发展明显 受限很多, 在这样的情况下, 只有各种因素共同作用才能 促进西部地区流通效率的提高。

以上的分析是基于整体显著的回归方程的粗略分析, 但是由于各个因素的不显著, 被解释变量存在不通过 $\mathrm{t}$ 检 验的情形, 这些表明解释变量之间存在多重共线性, 排除 多重共线性并进行逐步回归是了解影响地域流通效率最 主要因素的方法。

经过进一步的变量剔除, 排除了实验结果不显著的变 量, 本文得到了以下三个区域的流通效率影响因素的回归 方程:

$$
\begin{aligned}
\text { 东部: } \text { effect }_{1}= & 0.0204+0.1145 \text { urban }_{1}+0.1870 \text { gov }_{1} \\
& +0.6716 \text { int }_{1}
\end{aligned}
$$

对应解释变量的 $t$ 统计量为 $8.3239,2.3378,2.2331$, 概率为 $0.00,0.0415,0.0496$, 回归方程 $R^{2}=0.9955$, F统计 量概率为 0.00 。

$$
\text { 中部: } \begin{aligned}
\text { effect } & = \\
& -0.0128+0.1843 \text { urban }_{2}+0.1025 \text { gov }_{2} \\
& +0.7317 \text { int }_{2}
\end{aligned}
$$

对应解释变量的 $t$ 统计量为 $15.156,2.807,2.778$, 概率为 $0.00,0.0186,0.0195$, 回归方程 $R^{2}=0.9979, F$ 统计量概率为 0.00 。

$$
\begin{aligned}
& \text { 西部: } \text { effect }{ }_{3}=-0.0132+0.4381 \text { urban }_{3}+0.1113 \text { gov }_{3} \\
& +0.4784 \text { int }_{3}
\end{aligned}
$$

对应解释变量的 $t$ 统计量为7.599，9.886，3.707, 相 应的概率为 $0.00,0.00,0.004$ 。回归方程的 $R^{2}=0.9985$, $\mathrm{F}$ 统计量概率值为 0.00 , 在 $5 \%$ 的检验水平下, 系数估计值 的 $\mathrm{t}$ 检验都很明显。

以上回归方程表明, 在中国影响流通效率的主要因素 是城镇化率、政府参与程度和信息化程度。这三个变量分 别反映了宏观、行业、企业三个层面的影响。三个影响因 素对流通业发展都是正向的作用关系。而与地区差异相匹 配的回归结果主要反映在解释变量的系数不同, 即在不同 的地区, 影响区域的因素的作用程度不同。

东部与中部相比而言, 两者的回归模型反映了比较相 似的内容, 信息化程度对区域商品流通效率的提高有着比 较重要的影响。这主要是因为东部地区和中部地区的发展 越来越依靠更为高效化的企业效率。经济发展水平和政府 干预对流通的影响拉动作用随着流通业向着更高水平发 展而减弱。但是, 这并不意味政府可以放松管制, 任由流 通企业在市场环境下随意发展, 政府参与程度依旧是对流 通业发展有着重要的作用。特别是东部地区, 东部地区的 市场化水平相对较高, 在这样的情况下, 政府参与对效率 的影响更为敏感; 而政府参与程度相对要求较低的中部地 区，城镇化的发展则成为促进流通效率更为重要的因素。 不同于东部和中部地区, 西部的回归方程反映了相对 不同的内容, 这主要是因为西部地区的流通业发展水平低
于全国发展水平。西部地区流通业的发展需要良好的宏观 环境的支撑, 即在目前的情况下, 西部流通效率对工业和 市场发展的程度比较敏感, 反映在回归方程中表现为系数 占比将近 $50 \%$ 的城镇化率的影响。同时, 西部交通运输情 况的不便利也是限制其流通效率的一大障碍, 而城镇化率 与交通有着正向的关联关系。另外, 由于西部在地理位置 上的偏远，其基础设施、市场条件、对外开放程度等方面 的缺陷都是短时间无法弥补, 西部本身流通的发展对这些 因素也并不敏感; 西部的流通发展越来越依靠西部企业自 身的经营，依靠信息化发展促进企业升级。由于西部地区 发展的落后性, 政府参与便是带来西部流通效率的一个重 要因素, 政府调控物流成本, 有助于拉动流通业的发展。

\section{5. 结论与建议}

通过本文的实证结果发现, 影响各地区商贸流通效率 的因素基本一致, 主要是城镇化率、政府参与程度和信息 化程度, 这三个因素对商品流通效率都是正向的影响。但 是在不同的地区, 各类因素效率的拉动作用程度不一, 显 著性也有强弱之分。因此, 各地区应针对各自的特点提出 各有侧重的对策来提升效率水平。

城镇化率显著地影响效率水平, 而且是正向提升效率 水平的。该结论与经济规律相吻合, 在经济发展的过程中, 我们继续坚定不移地加快工业化和市场化进程。特别是在 西部地区, 着力进行西部大开发, 把握扩大内需这一战略 基点, 加快建立扩大消费者需求的长效机制, 释放居民尤 其是农村居民的消费潜力，使得经济基础能够匹配零售业 的进一步发展。

在 “互联网+”时代，信息化程度对流通效率起着关 键性的作用, 在良好的宏观环境和市场环境下, 中部和东 部地区企业信息化程度的发展越来越成为其流通效率竞 争的重要因素。提高信息化水平, 在对外开放中引进更适 合管理的信息技术手段，抢占更大的电子商务平台市场应 成为到多数企业战略发展的重要步骤。

以上回归方程表明，政府参与程度在不同地区的影响 程度相近，即政府对于不同地区的发挥着起着重要的作用。 政府强化区域商贸流通发展规划与体制改革, 打破区位制 约因素对于现代商贸流通效率问题, 政府应给予高度重视, 加快其商贸流通业健康发展的规划, 强化区域商贸流通体 制改革。我国政策决策层与主流理论界, 应正确认识我国 区域商贸流通效率现状, 对我国各区域商贸流通业发展规 划与政策法规加快制定、实施和完善。还应促进政府行政 体制改革进一步改革。政府应加强区域现代商贸流通交通 体系建设和开放性市场体系构建, 促进我国区域商贸流通 效率的提高与协调发展。

\section{参考文献}

[1] 曹元坤. 从经济增长方式内涵看经济增长方式转换 $[\mathrm{J}]$. 当 代财经, 2000, 11:11-15。 
[2] 陈宇峰, 章武滨. 中国区域商贸流通效率的演进趋势与影响 因素 [J]. 产业经济研究, 2015, 01:53-60。

[3] 冯海英. 我国区域商贸流通效率影响因素和发展对策 $[J]$. 商业经济研究, 2016, 08:31-33。

［4］依绍华. 流通产业公共支撑体系构成及政府介入方式 $[J]$. 中国流通经济, 2014, 03:17-22。

［5］姜增伟. 发展现代物流促进流通现代化 [J]. 中国流通经 济, 2008, 07:4-7。

[6] 王之泰. 流通成本及物流成本问题探讨 [J]. 中国流通经 济, 2013, 05:12-15。
[7] 章迪平, 孙敬水. 中国商品流通业市场结构与绩效实证研究 [J]. 价格月刊, 2009, 05:3-5。

［8］谢莉娟. 流通商主导供应链模式及其实现一一相似流通渠 道比较转化视角 $[\mathrm{J}]$. 经济理论与经济管 理, 2013, 07:103-112。

[9] 张弘. 信息化与中国流通创 新 $[\mathrm{J}]$. 财贸经 济, 2003, 10:58-62。

[10］孙金秀. 现代流通业效率指标体系的构建与评价一一基于 中国 30 个省际数据的比较分析 $[\mathrm{J}]$. 商业经济与管 理, 2014, 06:14-21。 